\title{
Adrenal Tumors: Are Gender Aspects Relevant?
}

\author{
Pier Francesco Alesina Martin K. Walz \\ Department of Surgery and Center of Minimally Invasive Surgery, Evang. Kliniken Essen-Mitte, Academic Teaching \\ Hospital of the University of Duisburg-Essen, Essen, Germany
}

\section{Keywords}

Gender - Adrenal tumor - Adrenalectomy .

Retroperitoneoscopic adrenalectomy · Gender medicine

\begin{abstract}
The distribution of malignant tumors is strongly related to gender due to sex-related organ and tissue differentiation. Neoplasias of the adrenal glands are relatively common and typically benign. Mainly based on our recently published contributions, we analyzed the influence of gender on type of tumors, complexity of surgery, and long-term outcome. Cortisol-secreting adrenal tumors are more often diagnosed in female patients, while the incidence of Conn's syndrome and pheochromocytoma is similar between male and female patients. Adrenalectomy is more difficult in male patients because of longer operating time and higher blood loss. The probability of cure in male patients with Conn's syndrome is significantly lower. Gender does not influence long-term results in adrenal hypercortisolism and pheochromocytomas.
\end{abstract}

(C) 2020 S. Karger AG, Basel

\section{Introduction}

The overall incidence of adrenal tumors is constantly increasing due to the widespread use of diagnostic modalities, such as computed tomography scans and magnetic resonance imaging. It ranges from 4 to $10 \%[1,2]$. A hormonal assessment is mandatory after diagnosis to prove or exclude overproduction of cortisol, aldosterone, or catecholamines. Moreover, according to the characteristics of the lesion and the clinical history, primary or sec- ondary adrenal malignancy should be taken into account. Gender is one of the most significant risk factors for cancer. It is well known that malignant tumors are more frequently diagnosed in male than in female patients $[3,4]$. There are only few reports in the literature investigating the effect of gender on adrenal tumors' epidemiology, pathology, and therapy $[5,6]$. The main aim of this article is to present the personal experience in gender-specific differences of adrenal tumors focusing on incidences and surgical therapy.

\section{Summary}

All data presented have been extracted from our previous publications with a specific focus on gender differences [7-13]. Additionally, a literature search (Medline database) for the keywords "gender," "adrenal tumor," and "adrenalectomy" has been performed and the data have been analyzed. According to the distribution of around 500 primary adrenal tumors operated at our institution (Fig. 1), the largest cohorts were tumors associated with hyperaldosteronism (32\%), pheochromocytomas (26\%), adrenal hypercortisolism (23\%), and non-functioning neoplasias (19\%). In the following, gender-related data will be analyzed separately for these 4 entities. The data from our previous studies were mainly based on results obtained by the retroperitoneoscopic approach invented in 1994 [14].

\section{Hyperaldosteronism}

In 2008, we presented the results of surgery in a group of 183 patients affected by Conn's syndrome and oper- 
Fig. 1. Distribution of primary adrenal tumors (Essen, 1994-2006) [8].

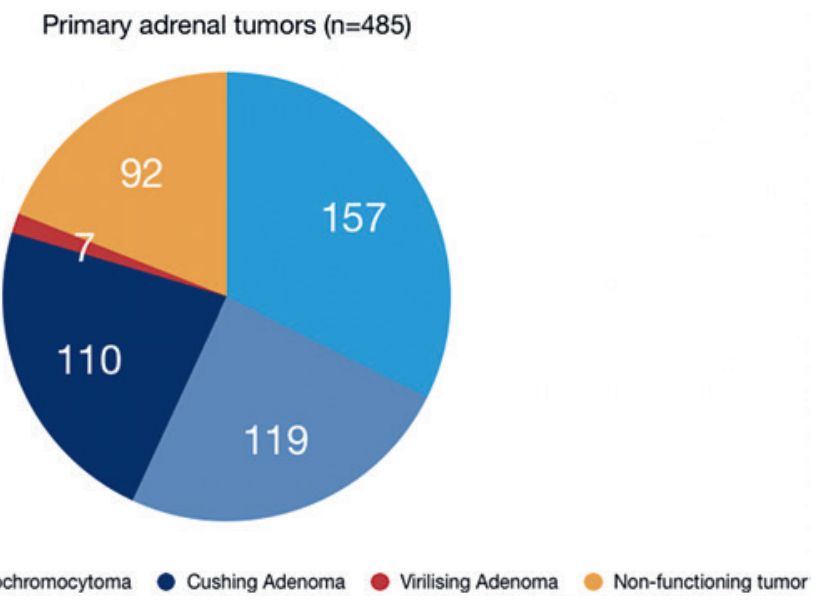

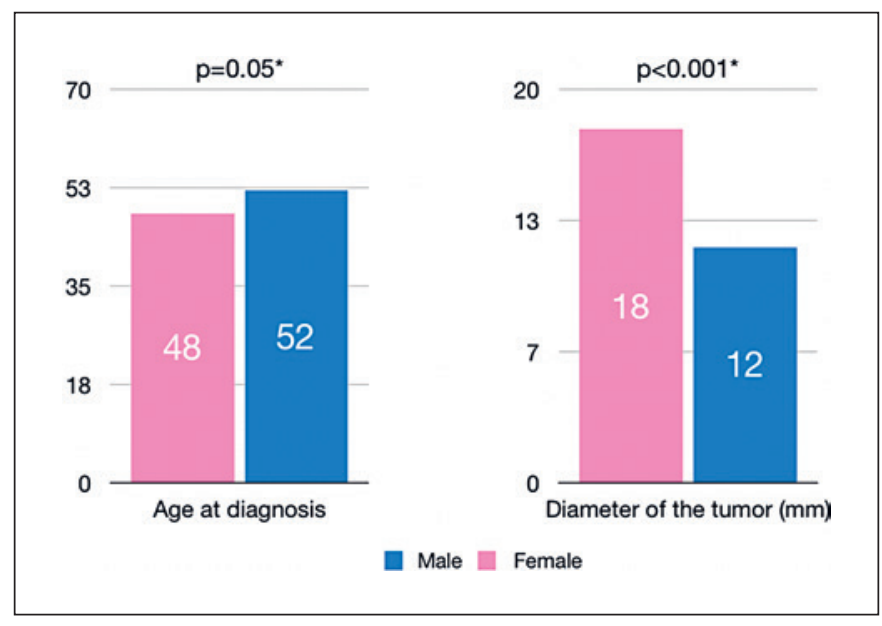

Fig. 2. Age and tumor diameter of patients with Conn's syndrome [9]. * Mann-Whitney test was used for the statistical analysis; $p<$ 0.05 was considered statistically significant.

ated by the retroperitoneoscopic route [9]. There were 102 females and 81 males with a female/male ratio of 1.2: 1. The mean age at the time of surgery was $49.6 \pm 12.8$ years (range 19-78). There was a difference regarding age and tumor diameter between male and female patients (Fig. 2). Operating time was significantly longer $(p<$ $0.001)$ in male patients (67 $\pm 36 \mathrm{~min}$ [range $25-230$ ] vs. $51 \pm 27$ min [range 20-155]); intraoperative blood loss did not differ ( $20 \pm 38$ vs. $10 \pm 17 \mathrm{~mL} ; p=0.08$ ). Long-term results (follow-up: mean $59 \pm 40$ months [range 6-159]) were obtained in 160 patients. In univariate analysis, cure (normotension without medication) was significantly influenced by patients' sex (male $[n=75]$ vs. female $[n=$ 85]: 16 vs. $42 \%$; $p<0.001$ ). This difference was still present when considering the subgroup of patients older than 50 years and, therefore, with a longer duration of arterial hy- pertension (male $[n=38]$ vs. female $[n=34]: 5$ vs. $29 \%$; $p<0.01)$. These gender differences may have been related to an increased incidence of adrenal hyperplasia in the male group.

The observation of a higher incidence in female patients was not confirmed in other studies $[15,16]$. In a large cohort from the German Conn Registry, there were 327 males out of 555 patients (female/male ratio of $0.7: 1$ ). The main limit of this multi-centric study is the high heterogeneity in the diagnostic evaluation of primary hyperaldosteronism [15]. Nevertheless, a second, recently published multi-centric study, including 1,625 patients subtyped with adrenal vein sampling, confirmed the higher incidence in males (female/male ratio of 0.65:1) [16].

Apostolopoulou et al. [17] reported on anxiety and depression in hyperaldosteronism patients analyzed by 2 questionnaires (general anxiety disorder questionnaire [GAD-7] and brief patient health questionnaire [PHQD]). This study included 132 patients with 3 different treatment groups. Twenty-seven patients were untreated, 56 patients had received a mineralocorticoid antagonist for at least 5 years, and 49 patients had had unilateral adrenalectomy at least 4 years before. The prevalence of depressive disorders assessed by PHQD was $50 \%$ for untreated patients, $42 \%$ for patients under medical treatment, and $38 \%$ after adrenalectomy. The mean values of the PHQD ( $\geq 5$ points in the questionnaire indicating depression) were significantly higher in patients of the untreated $(5.95 \pm 4.82 ; p=0.009)$ and mineralocorticoid antagonist-treated $(5.10 \pm 5.13 ; p=0.008)$ groups compared to the reference population $(3.56 \pm 4.08)$. The values were similar to the reference population in the adrenalectomy group (3.98 $\pm 3.47 ; p=0.508)$. A higher proportion of female patients with anxious and depressive symptoms in all 3 groups was found with statistical significance only 
for the group of untreated patients $(8.86 \pm 4.2$ for females vs. $4.38 \pm 4.5$ for males; $p=0.045)$. Moreover, female patients had a tendency for higher mean anxiety levels as assessed by the GAD-7 questionnaire than men, but this difference was not statistically significant. Adrenalectomy was found to be associated with the best psychopathology scores and a significantly lower concentration of aldosterone. Mineralocorticoid antagonist treatment seemed to be inferior to adrenalectomy in terms of outcome.

\section{Pheochromocytoma}

In 2006, we described a series of 126 patients with pheochromocytoma and/or paragangliomas with a slight predominance of male patients [7]. Underlying hereditary diseases were known in 42 patients (33\%). There was no difference in terms of tumor diameter ( $36 \mathrm{vs.} 37 \mathrm{~mm}$ ). In the subgroup of unilateral tumors operated by the retroperitoneoscopic approach, operating time (males vs. females: 96 vs. $65 \mathrm{~min} ; p<0.001$ ) and intraoperative blood loss (males vs. females: 61 vs. $20 \mathrm{~mL} ; p<0.01$ ) were significantly higher in male patients. In the pheochromocytoma cohort with more hereditary diseases (bilateral, children), we saw a clear predominance of male patients $[11,13]$. In 66 patients ( $86 \%$ hereditary) with bilateral pheochromocytomas, 45 were male $(68 \%)$. The mean age at diagnosis was 40 years in male and 47.4 years in female patients $(p=0.008)$. Corresponding observations have been found in our study on children with chromaffin tumors: in a group of 42 patients younger than 20 years, 37 children or adolescents (88\%) suffered from inherited diseases and 33 were male (79\%). Such a higher incidence of chromaffin tumors in males with a higher incidence of hereditary diseases was not confirmed in other cohorts with adult patients. Recently, data from the EuropeanAmerican-Asian-Bilateral-Pheochromocytoma-Registry including 625 patients, $96 \%$ with defined genetic disorders, reported a female/male ratio of 0.92:1 (300 females, 325 males) [18]. The higher incidence of chromaffin tumors in young male patients needs further investigations, preferably in a multi-centric setting. We did not see any gender-related differences in long-term outcome, especially for primary malignant or recurrent pheochromocytomas $[7,11,13]$.

Lai et al. [6] analyzed differences in the clinical presentation of catecholamine-secreting tumors. The following signs and symptoms were assessed: blood pressure and heart rate at referral, headache, sweating, palpitations, anxiety or nervousness, tremors (hands/arms, feet/legs, or other), pain (chest, abdomen, back, or other), numbness, nausea/vomiting, weakness/fatigue, changes in energy level, weight change, warmth or heat intolerance, visual disturbances, dizziness, change in bowel function, pallor or flushing, and seizure. A comparison of total

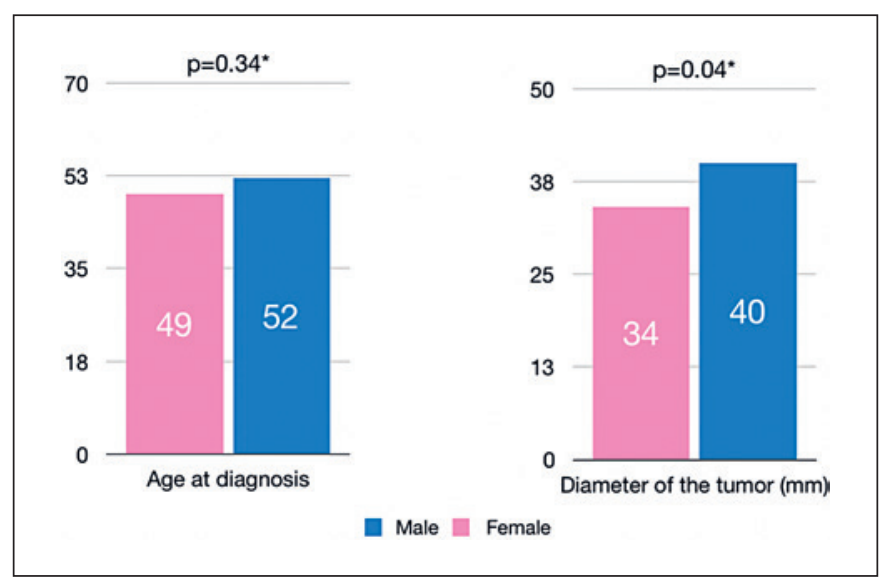

Fig. 3. Age and tumor diameter of patients with Cushing's syndrome (non-published data from [10]). * Mann-Whitney test; $p<$ 0.05 was considered statistically significant.

symptom scores (calculated as the ratio of the total number of affirmative responses out of the possible symptoms) between genders showed significant differences ( 12.0 vs. $7.8 ; p=0.0001$ ). Female patients reported significantly more headache ( 80 vs. $52 \%$ ), dizziness ( 83 vs. $39 \%$ ), anxiety ( 85 vs. $50 \%$ ), tremor ( 64 vs. $33 \%$ ), weight change ( 88 vs. $43 \%$ ), numbness ( 57 vs. $24 \%$ ), and changes in energy level ( 89 vs. $64 \%$ ). This could be related to distinct catecholamine receptor sensitivity. Gender differences have been observed for adrenoceptor responsiveness, with women having greater $\alpha 2$ - and $\beta 2$-adrenergic receptor sensitivity than men [19]. Furthermore, in animal studies, female rats exhibited greater $\alpha 2$-adrenergic receptor protein levels than their male counterparts [20].

\section{Hypercortisolism}

Differently to pheochromocytomas, ACTH-independent hypersecretion of cortisol (Cushing's syndrome) affects predominantly female patients. In our study including 170 patients, there were 153 females and 17 males (mean age: $51.8 \pm 13.8$ years [range $12-84$ ]) with a female/ male ratio of 9:1 [10]. There was no significant difference regarding age at diagnosis, although the diameter of the tumor was significantly larger in males (Fig. 3). The operating time did not differ between male (66 min [range $30-105])$ and female (58 min [range 20-235]) patients $(p=0.06)$. The intraoperative blood loss was also not significantly different ( 14.1 vs. $20.9 \mathrm{~mL} ; p=0.27)$. In the same study, we presented the long-term results of surgery in 163 out of 170 patients with at least 6 months of followup. One female patient with overt hypercortisolism showed a recurrent/persistent hypercortisolism [10]. In a recent study analyzing the subgroup of patients affected by macronodular bilateral hyperplasia (42 patients), the gender distribution was around 1:3 (12 male) [12]. The relatively higher proportion of male patients in this study 
Fig. 4. Gender-specific differences in retroperitoneal anatomy: the radiological features typically differ between male and female patients. a, c CT scan of a female patient showing bilateral adrenal tumors, embedded in small amounts of retroperitoneal fatty tissue. The left kidney is without signs of perirenal fibrosis. $\mathbf{b}, \mathbf{d}$ CT and MRI of male patients with both kidneys surrounded by more fatty tissue and perirenal adhesions (red arrows), which are more typical in males.
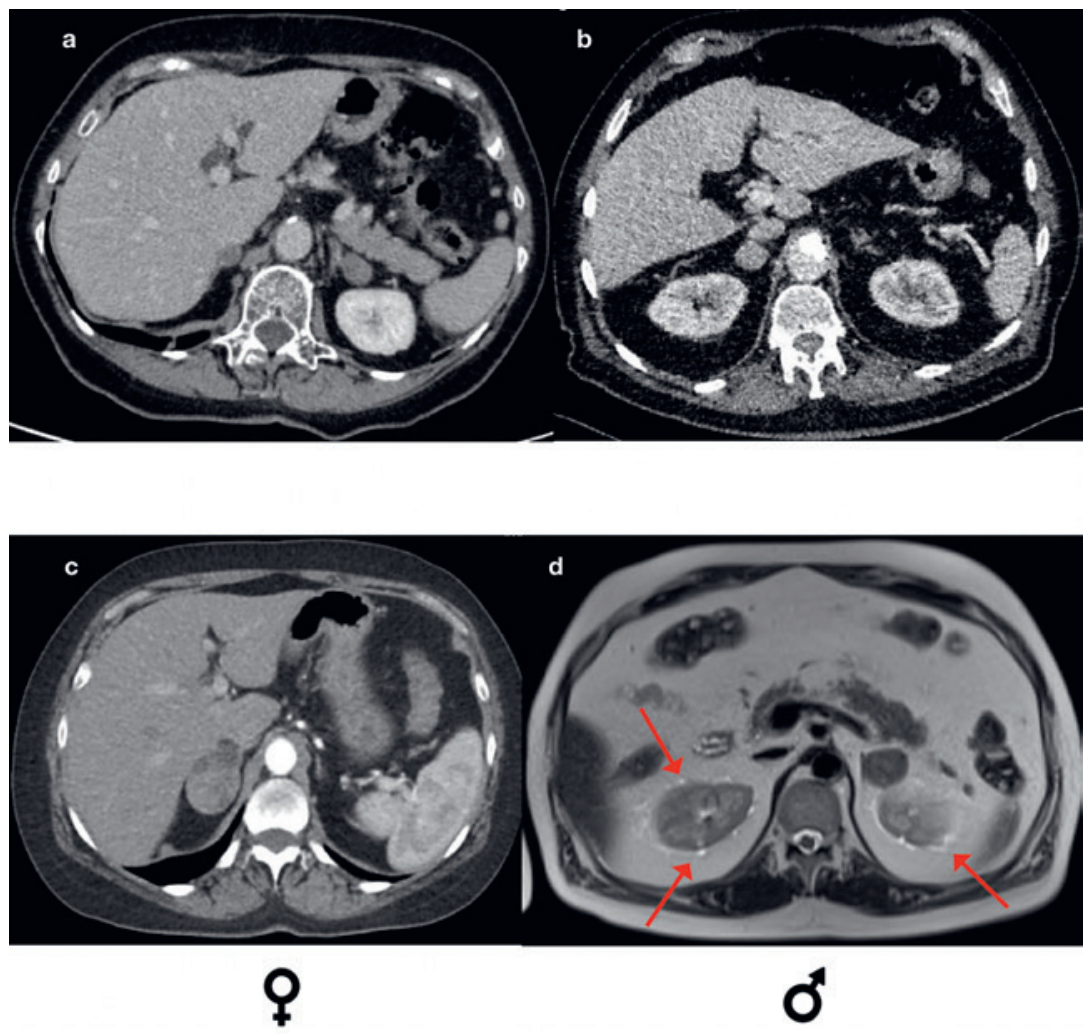

may be based on the increased ratio of subclinical Cushing's syndrome in macronodular hyperplasias when compared to adrenal adenomas.

Studies analyzing gender-specific differences in the clinical presentation of patients with hypercortisolism focused on Cushing's disease only. Zilio et al. [21] observed no differences between males and females regarding age at diagnosis, disease duration, and body mass index. Men presented higher urinary free cortisol values $(p<0.001)$ and ACTH values than women $(p<0.05)$. Some complications of disease were more frequent or more severe in men, in particular hypokalemia $(p<0.05)$, hypercoagulable state, and osteoporosis at lumbar spine $(p<0.01)$, with consequent higher risk of vertebral fractures. Moreover, male gender was found to be an independent risk factor for dyslipidemia, severity of hypertension, lumbar osteoporosis, and fractures.

\section{Non-Functioning Adrenal Tumors}

In recent publications, we did not analyze the gender distribution in non-functioning adrenal neoplasias. Nevertheless, other clinical studies have shown that these tumors are more frequent in females, with a mean female/ male ratio of 1.4:1 (range 0.9-2.5) [22]. For the purpose of this study, we extrapolated data regarding the operating time of 92 patients with incidentaloma included in our overview of retroperitoneoscopic adrenalectomy published in 2006 [8]. The procedures took longer in male than in female patients ( $78 \pm 43$ vs. $59 \pm 36 \mathrm{~min}$, respectively; $p<0.001$ ).

\section{Gender-Related Characteristics of Retroperitoneal Anatomy}

The common thread of our retrospective analysis is the observation of a longer operation time in male patients. This finding started with our early study from 2006 with more than 500 adrenal lesions (male: $78 \pm 43 \mathrm{~min}$; female: $59 \pm 36 \mathrm{~min} ; p<0.001$ ) and was repeatedly found [7-11, 13]. Three different anatomical characteristics may be the reason for these consistent data: (1) the presence of adherent perinephric fat, so-called sticky fat, which can limit mobilization of the kidney and isolation of the tumor [23] is more often encountered in male patients; (2) the bigger dimension of male patients and, therefore, the longer working distance connected to a deeper location of the tumors; and (3) the presence of a larger amount of retroperitoneal fatty tissue in males (Fig. 4). The latter was also indicated in a recent retrospective study of 83 patients who underwent retroperitoneoscopic adrenalectomy, together with the side of the tumor, as an independent predictor of increased operative time in the multivariable analysis [24]. Moreover, according to our experi- 
ence, the presence of perinephric stranding, defined as a linear area of soft tissue attenuation in the perinephric space (red arrows in Fig. 4), is generally associated with the presence of adherent perinephric fat and generally more difficult dissection.

\section{Key Messages}

In our patients, pheochromocytomas were more frequent in males, while other secreting benign adrenal tumors and incidentalomas were more often diagnosed in females. This observation is confirmed in the literature with the exception of Conn's syndrome that seems to be more frequent in males. Minimally invasive retroperitoneoscopic adrenalectomy is more difficult in males in terms of a longer operating time and higher blood loss.
The probability of cure in patients with Conn's syndrome is significantly related to gender, as male patients are more likely to present with persistent disease.

\section{Disclosure Statement}

The authors have no conflicts of interest to declare.

\section{Funding Sources}

There were no funding sources.

\section{Author Contributions}

P.F.A. and M.K.W. contributed equally to the manuscript.

\section{References}

1 Mansmann G, Lau J, Balk E, Rothberg M, Miyachi Y, Bornstein SR. The clinically inapparent adrenal mass: update in diagnosis and management. Endocr Rev. 2004 Apr;25(2): 309-40.

2 Jason DS, Oltmann SC. Evaluation of an Adrenal Incidentaloma. Surg Clin North Am. 2019 Aug;99(4):721-9.

3 Cook MB, Dawsey SM, Freedman ND, Inskip PD, Wichner SM, Quraishi SM, et al. Sex disparities in cancer incidence by period and age. Cancer Epidemiol Biomarkers Prev. 2009 Apr;18(4):1174-82.

4 Siegel R, Ward E, Brawley O, Jemal A. Cancer statistics, 2011: the impact of eliminating socioeconomic and racial disparities on premature cancer deaths. CA Cancer J Clin. 2011 Jul-Aug;61(4):212-36.

5 Audenet F, Méjean A, Chartier-Kastler E, Rouprêt M. Adrenal tumours are more predominant in females regardless of their histological subtype: a review. World J Urol. 2013 Oct;31(5):1037-43.

6 Lai EW, Perera SM, Havekes B, Timmers HJ, Brouwers FM, McElroy B, et al. Gender-related differences in the clinical presentation of malignant and benign pheochromocytoma. Endocrine. 2008 Aug-Dec;34(1-3):96-100.

7 Walz MK, Alesina PF, Wenger FA, Koch JA, Neumann HP, Petersenn S, et al. Laparoscopic and retroperitoneoscopic treatment of pheochromocytomas and retroperitoneal paragangliomas: results of 161 tumors in 126 patients. World J Surg. 2006 May;30(5):899908.

8 Walz MK, Alesina PF, Wenger FA, Deligiannis A, Szuczik E, Petersenn S, et al. Posterior retroperitoneoscopic adrenalectomy results of 560 procedures in 520 patients. Surgery. 2006 Dec;140(6):943-8; discussion 948-50.

9 Walz MK, Gwosdz R, Levin SL, Alesina PF, Suttorp AC, Metz KA, et al. Retroperitoneoscopic adrenalectomy in Conn's syndrome caused by adrenal adenomas or nodular hy- perplasia. World J Surg. 2008 May;32(5):84753.

10 Alesina PF, Hommeltenberg S, Meier B, Petersenn S, Lahner H, Schmid KW, et al. Posterior retroperitoneoscopic adrenalectomy for clinical and subclinical Cushing's syndrome. World J Surg. 2010 Jun;34(6):1391-7.

11 Alesina PF, Hinrichs J, Meier B, Schmid KW, Neumann HP, Walz MK. Minimally invasive cortical-sparing surgery for bilateral pheochromocytomas. Langenbecks Arch Surg. 2012 Feb;397(2):233-8.

12 Lowery AJ, Seeliger B, Alesina PF, Walz MK. Posterior retroperitoneoscopic adrenal surgery for clinical and subclinical Cushing's syndrome in patients with bilateral adrenal disease. Langenbecks Arch Surg. 2017 Aug; 402(5):775-85.

13 Walz MK, Iova LD, Deimel J, Neumann HP, Bausch B, Zschiedrich S, et al. Minimally Invasive Surgery (MIS) in Children and Adolescents with Pheochromocytomas and Retroperitoneal Paragangliomas: experiences in 42 Patients. World J Surg. 2018 Apr;42(4):102430.

14 Walz MK, Peitgen K, Hoermann R, Giebler RM, Mann K, Eigler FW. Posterior retroperitoneoscopy as a new minimally invasive approach for adrenalectomy: results of 30 adrenalectomies in 27 patients. World J Surg. 1996 Sep;20(7):769-74.

15 Schirpenbach C, Segmiller F, Diederich S, Hahner S, Lorenz R, Rump LC, et al. The diagnosis and treatment of primary hyperaldosteronism in Germany: results on 555 patients from the German Conn Registry. Dtsch Arztebl Int. 2009 May;106(18):305-11.

16 Rossi GP, Rossitto G, Amar L, Azizi M, Riester A, Reincke M, et al.; Clinical Outcomes of 1625 Patients With Primary Aldosteronism Subtyped With Adrenal Vein Sampling. Clinical Outcomes of 1625 Patients With Primary Aldosteronism Subtyped With Adrenal Vein Sampling. Hypertension. 2019 Oct;74(4): 800-8.
17 Apostolopoulou K, Künzel HE, Gerum S, Merkle K, Schulz S, Fischer E, et al. Gender differences in anxiety and depressive symptoms in patients with primary hyperaldosteronism: a cross-sectional study. World J Biol Psychiatry. 2014 Jan;15(1):26-35.

18 Neumann HP, Tsoy U, Bancos I, Amodru V, Walz MK, Tirosh A, et al.; International Bilateral-Pheochromocytoma-Registry Group. Comparison of Pheochromocytoma-Specific Morbidity and Mortality Among Adults With Bilateral Pheochromocytomas Undergoing Total Adrenalectomy vs Cortical-Sparing Adrenalectomy. JAMA Netw Open. 2019 Aug; 2(8):e198898.

19 Luzier AB, Nawarskas JJ, Añonuevo J, Wilson MF, Kazierad DJ. The effects of gender on adrenergic receptor responsiveness. J Clin Pharmacol. 1998 Jul;38(7):618-24.

20 Pujol E, Rodríguez-Cuenca S, Frontera M, Justo R, Lladó I, Kraemer FB, et al. Genderand site-related effects on lipolytic capacity of rat white adipose tissue. Cell Mol Life Sci. 2003 Sep;60(9):1982-9.

21 Zilio M, Barbot M, Ceccato F, Camozzi V, Bilora F, Casonato A, et al. Diagnosis and complications of Cushing's disease: gender-related differences. Clin Endocrinol (Oxf). 2014 Mar;80(3):403-10.

22 Barzon L, Sonino N, Fallo F, Palu G, Boscaro M. Prevalence and natural history of adrenal incidentalomas. Eur J Endocrinol. 2003 Oct; 149(4):273-85.

23 Davidiuk AJ, Parker AS, Thomas CS, Leibovich $\mathrm{BC}$, Castle EP, Heckman MG, et al. Mayo adhesive probability score: an accurate image-based scoring system to predict adherent perinephric fat in partial nephrectomy. Eur Urol. 2014 Dec;66(6):1165-71.

24 Pearlstein SS, Kuo JH, Chabot JA, Lee JA. Periadrenal Volume is a Better Predictor of Prolonged Operative Time in Laparoscopic Retroperitoneal Adrenalectomy than BMI. World J Surg. 2019 Dec. https://doi. org/10.1007/s00268-019-05324-0. 